\title{
The infrared measurements of damages of laser-processed carbon fiber reinforced plastics
}

\author{
by M. Muramatsu*, Y. Harada*, T. Suzuki and H. Niino
}

\begin{abstract}
* National Institute of Advanced Industrial Science and Technology, 1-2-1 Namiki, Tsukuba, Ibaraki 305-8564,
\end{abstract} Japan, mayu-muramatsu@aist.go.jp

\begin{abstract}
Recently, laser processing of carbon fiber reinforced plastic (CFRP) attracts attentions due to the high processing speed and less tool wear. The evaluation of damages generated in CFRPs during laser processing is important. Infrared thermography is known as a non-destructive testing method to evaluate defects in structures especially for health monitoring. Defects are detected by temperature or stress distributions on surfaces obtained by an infrared camera. This method is considered to be useful to evaluate the damages in CFRPs introduced by laser processing. In this study, the authors report the stress distributions of CFRPs processed by laser. The stress distribution was obtained by infrared thermography. Subsequently, the distribution is discussed in terms of the heat-affected zone (HAZ).
\end{abstract}

\section{Introduction}

Carbon fiber reinforced plastic (CFRP) is an advanced composite material consisting of resin and carbon fiber. The use of CFRP is extended to vehicles and airplanes since it has remarkable specific strength and specific rigidity. It allows reducing the weights of the structures, which leads to improvement of energy efficiency. Processing methods for CFRP are also important. The most popular method to process CFRP is mechanical cutting. Recently, laser cutting attracts attention due to the high processing speed and less tool wear [1, 2]. Harada, et al [3] reported about CFRPs which was cut by a CO2 gas laser $(10.6 \mu \mathrm{m}, 800 \mathrm{~W}, 20 \mathrm{kHz}, 1 \mathrm{~m} / \mathrm{min})$, single-mode fiber laser $(1.07 \mu \mathrm{m}, 300 \mathrm{~W}$ or $2000 \mathrm{~W}$, continuous wave, $1 \mathrm{~m} / \mathrm{min}$ or $7 \mathrm{~m} / \mathrm{min}$ ) and so on. They mentioned that these specimens showed lower tensile strength and fatigue strength than milling-cut specimens since specimens had thermal damages named as heat-affected zone (HAZ). Non-destructive testing (NDT) methods are considered to be useful to evaluate damages in CFRPs introduced by laser processing since HAZ is a kind of damages. Infrared thermography is known as a NDT method to evaluate defects in CFRP [4]. Defects are detected by temperature distributions on surfaces taken by an infrared camera. Additionally, stress distributions can be calculated based on the temperature distributions according to the equation of thermoelastic stress. HAZ induced by laser processing is considered to be evaluated by the stress distributions obtained by infrared measurement. However, there is no study of the infrared measurement of the damages of laser-processed CFRP. In this study, the authors report the stress distribution of CFRP processed by laser using infrared measurement and discuss it especially in terms of the HAZ.

\section{Experimental procedure}

The JIS71694 specimens were cut from the plate of $0 / 90^{\circ}$ cross ply CFRP with PAN-based carbon fiber. To cut the CFRP specimens, a single-mode fiber laser was used in the processing speed of $1.0 \mathrm{~m} / \mathrm{min}$ with continuous wave, the mean power of $350 \mathrm{~W}$ and the assist gas of $\mathrm{N}_{2}$. Subsequently, fatigue tests were conducted with electro-hydraulic materials testing machine (MTS). The maximum load was $10 \mathrm{MPa}$, the stress ratio $R=0.1$ and frequency $f=5 \mathrm{~Hz}$. The temperature distributions were taken by infrared camera SC7500 (FLIR) whose temperature resolution was $0.018{ }^{\circ} \mathrm{C}$. The observation was conducted with $\mathrm{G} 1$ micro lens (FLIR) to take the high resolution images, i.e., minimum spatial resolution is $30 \mu \mathrm{m}$. The obtained images were introduced into thermoelastic stress analysis software altir LI (FLIR) and the stress distributions were calculated, X-ray CT images were also obtained to evaluate the stress distribution with HAZ. The X-ray measurements were carried out with the equipment of TDM1000H-S $\mu / 1600 \mathrm{H}-\mathrm{II}$ (Yamato Scientific Co.,Ltd.).

\section{Results and discussion}

Figure 1 shows the stress distribution of CFRP processed by the fiber laser. We also obtained X-ray images of CFRP from the directions 1 and 2 shown in figure 2. Figures $3(a)$ and (b) are the observed images from direction 1 and 2 , respectively. The both figures were obtained at the edge area of CFRP specimen. In figure 1, it can be seen that the numerous of fibers were exposed from the specimen at the cutting edge. Such exposed fibers were observed at the edge of the specimen in the figure 3 (b). Additionally, delaminations and debondings were seen inside CFRP in figure 3 (b). In figure 1, the depressed stress zone was observed at the edge of the specimen. The length of the zone area was 1.0$2.0 \mathrm{~mm}$. In figure $3(\mathrm{a})$, the HAZ whose width was about $0.5 \mathrm{~mm}$ was found. The size of the area whose stress was depressed corresponded to the size of the HAZ in the X-ray images. Comparison of the stress distribution in figure 1 and 


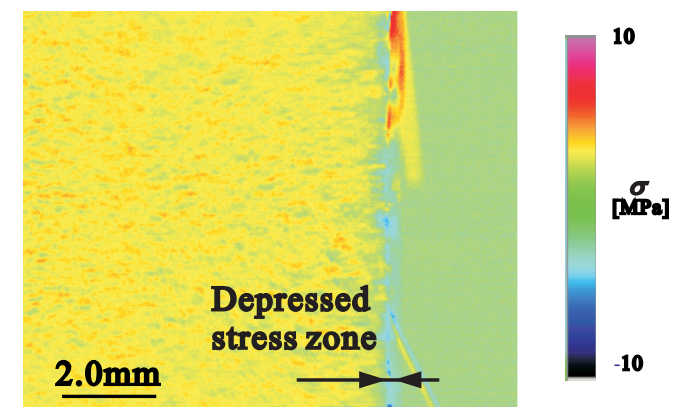

Fig. 1. Stress distributions of CFRPs processed by fiber laser by infrared measurement

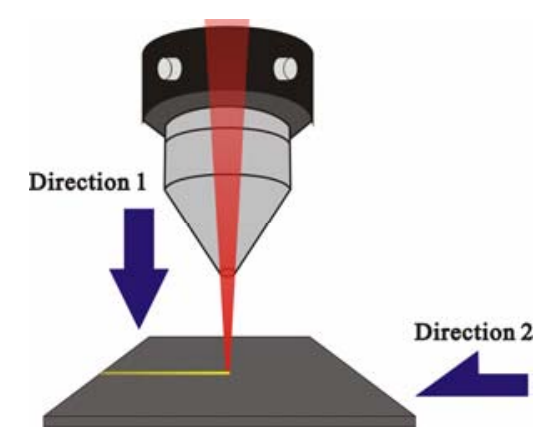

Fig. 2. Schematic illustration of observation directions toward laser processed CFRP

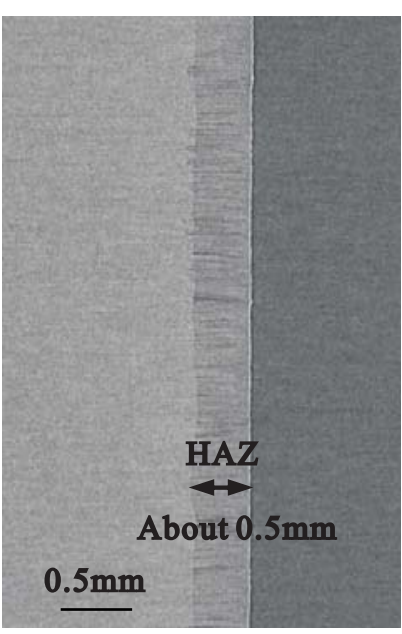

(a) View from the dirction 1

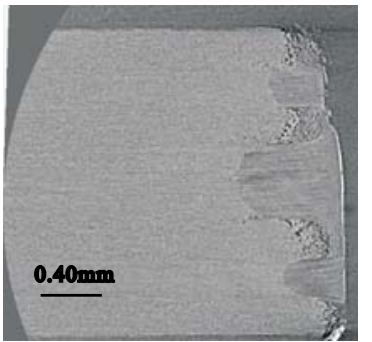

(b) View from the direction 2

Fig. 3. X-ray images of CFRP processed by fiber laser

X-ray images in figure 3 provides the following supposition: The epoxy resin in the cutting edge and the neighboring area was evaporated during the laser processing. Such evaporation led to the delaminations and debondings in CFRP, which made the area unable to bear the load. The depressed stress zone at the cutting edge area is considered to have induced the depressed strength [3].

\section{Conclusions}

The damages of the $0 / 90^{\circ}$ cross ply CFRP with PAN-based carbon fiber generated by single-mode fiber laser processing was evaluated by taking the stress distributions with infrared measurement. The X-ray CT images were also obtained to discuss the stress distribution in terms of the HAZ. The stress distribution showed the sizes of the depressed stress zone and HAZ were coincident with each other. The depressed stress zone is considered to associate with the conventionally-reported depressed strength in laser processed CFRP.

\section{Acknowledgement}

This research was partially supported by High-Power Pulsed Fiber Laser and Processing Technology Project from New Energy and Industrial Technology Development Organization (NEDO) of Japan.

\section{REFERENCES}

[1] Niino H., "The Japanese Way of Knowledge Transfer", Proceeding of 31st International Congress on Applications of Lasers \& Electro-Optics, C105, 31, 2012.

[2] Niino H., Kurosaki R., "Laser cutting of carbon fiber reinforced plastics (CFRP) by UV pulsed laser ablation", Proceedings of SPIE, vol. 7920, 792019, 2011.

[3] Harada Y., Kawai K., Suzuki T., Teramoto T., "Evaluation of Cutting Process on the Tensile and Fatigue Strength of CFRP Composites", Materials Science Forum, vols. 706-709, pp. 649-654, 2012.

[4] Maldaque X.P.V., "Theory and Practice of Infrared Technology for Nondestructive Testing", John Willy \& Sons, 2001. 